\section{AB013. Management of germ cell tumors: a case with growing teratoma syndrome}

\section{Zhitao Gu}

Department of Thoracic Surgery, Shanghai Chest Hospital, Shanghai Jiao Tong University, Shanghai 200030, China

Correspondence to: Zhitao Gu. Department of Thoracic Surgery, Shanghai Chest Hospital, Shanghai Jiao Tong University, 241 Huaihai Rd West, Shanghai 200030, China. Email: guzhitao0717@hotmail.com.

\begin{abstract}
The growing teratoma syndrome in patients with anterior mediastinal germ cell tumors were rare. Here, we report a patient with primary anterior mediastinal malignant mixed germ cell tumor that exhibited growing teratoma syndrome after initiation chemotherapy. A 28-year-old man is admitted to the hospital complaining of dyspnea. Chest computed tomography (CT) showed a huge heterogeneous anterior mediastinal mass $(20 \mathrm{~cm}$ in longest direction). The tumor compressed the left lung, heart and great vessels. The $\alpha$-fetoprotein (AFP) is higher than $3,000 \mathrm{ng} / \mathrm{mL}$, the $\beta$-human chorionic gonadotropin
\end{abstract}

( $\beta$-HCG) level is increased to $49.7 \mathrm{ng} / \mathrm{mL}$. Coreneedle biopsy confirmed the diagnosis of teratoma with nonseminomatous germ cell tumors. The patient was administered two rounds of bleomycin, etoposide, cisplatin (BEP) chemotherapy, but the mass grew despite Serum AFP was rapidly declining $(171 \mathrm{ng} / \mathrm{mL})$. And CT scan revealed a notable enlargement of the tumor. Surgical tumor resection was performed through a median sternotomy. The tumor was adherent to the pericardium, bilateral mediastinum pleura, left upper lobe, and left phrenic nerve. The tumor was completely resected including pericardiectomy, resection of the left phrenic nerve, and left upper lobectomies. The pathologic examination revealed malignant mixed germ cell tumor with extensive areas of chemotherapy-induced necrosis which was consisted with mature teratoma, immature teratoma and embryonal carcinoma. The patient was alive without recurrence at 6 months after two rounds of adjuvant chemotherapy.

Keywords: Anterior mediastinal germ cell tumors; growing teratoma syndrome; chemotherapy; tumor resection

doi: 10.21037/shc.2019.AB013

Cite this abstract as: Gu Z. Management of germ cell tumors: a case with growing teratoma syndrome. Shanghai Chest 2019;3:AB013. 
Page 2 of 2

Shanghai Chest, 2019 